\title{
Research Progress of Cryogenic Materials for Storage and Transportation of Liquid Hydrogen
}

\author{
Yinan Qiu ${ }^{1,2, *}$, Huan Yang ${ }^{3}$, Lige Tong ${ }^{1}\left(\mathbb{D}\right.$ and Li Wang ${ }^{1}(\mathbb{D}$ \\ 1 School of Energy and Environmental Engineering, University of Science and Technology Beijing, \\ Beijing 100083, China; tonglige@me.ustb.edu.cn (L.T.); liwang@me.ustb.edu.cn (L.W.) \\ 2 State Key Laboratory of Technologies in Space Cryogenic Propellants, Beijing 100028, China \\ 3 Beijing Institute of Tracking and Communication Technology, Beijing 100094, China; yanghuan@bittt.cn \\ * Correspondence: b20190060@xs.ustb.edu.cn; Tel./Fax: +86-13811629985
}

Citation: Qiu, Y.; Yang, H.; Tong, L.; Wang, L. Research Progress of Cryogenic Materials for Storage and Transportation of Liquid Hydrogen. Metals 2021, 11, 1101. https:// doi.org/10.3390/met11071101

Academic Editors: Michel Arrigoni, Babak Shalchi Amirkhiz and Tomasz Czujko

Received: 21 May 2021

Accepted: 6 July 2021

Published: 10 July 2021

Publisher's Note: MDPI stays neutral with regard to jurisdictional claims in published maps and institutional affiliations.

Copyright: (c) 2021 by the authors. Licensee MDPI, Basel, Switzerland. This article is an open access article distributed under the terms and conditions of the Creative Commons Attribution (CC BY) license (https:// creativecommons.org/licenses/by/ $4.0 /)$.

\begin{abstract}
Liquid hydrogen is the main fuel of large-scale low-temperature heavy-duty rockets, and has become the key direction of energy development in China in recent years. As an important application carrier in the large-scale storage and transportation of liquid hydrogen, liquid hydrogen cryogenic storage and transportation containers are the key equipment related to the national defense security of China's aerospace and energy fields. Due to the low temperature of liquid hydrogen (20 K), special requirements have been put forward for the selection of materials for storage and transportation containers including the adaptability of materials in a liquid hydrogen environment, hydrogen embrittlement characteristics, mechanical properties, and thermophysical properties of liquid hydrogen temperature, which can all affect the safe and reliable design of storage and transportation containers. Therefore, it is of great practical significance to systematically master the types and properties of cryogenic materials for the development of liquid hydrogen storage and transportation containers. With the wide application of liquid hydrogen in different occasions, the requirements for storage and transportation container materials are not the same. In this paper, the types and applications of cryogenic materials commonly used in liquid hydrogen storage and transportation containers are reviewed. The effects of low-temperature on the mechanical properties of different materials are introduced. The research progress of cryogenic materials and low-temperature performance data of materials is introduced. The shortcomings in the research and application of cryogenic materials for liquid hydrogen storage and transportation containers are summarized to provide guidance for the future development of container materials. Among them, stainless steel is the most widely used cryogenic material for liquid hydrogen storage and transportation vessel, but different grades of stainless steel also have different applications, which usually need to be comprehensively considered in combination with its low temperature performance, corrosion resistance, welding performance, and other aspects. However, with the increasing demand for space liquid hydrogen storage and transportation, the research on high specific strength cryogenic materials such as aluminum alloy, titanium alloy, or composite materials is also developing. Aluminum alloy liquid hydrogen storage and transportation containers are widely used in the space field, while composite materials have significant advantages in being lightweight. Hydrogen permeation is the key bottleneck of composite storage and transportation containers. At present, there are still many technical problems that have not been solved.
\end{abstract}

Keywords: liquid hydrogen; cryogenic storage and transportation container; cryogenic materials; mechanical properties

\section{Introduction}

Liquid hydrogen is the main fuel for low-temperature rockets, especially large-scale low-temperature heavy-duty rockets such as the cz-7 series, cz-5 series in service, cz- 8 , and the new generation of manned rockets in future planning that need to use liquid hydrogen 
as a propellant. With the development of deep space exploration, manned lunar landings, space station missions, Beidou networking, Internet satellite systems, and other missions, the scale of its use shows a strongly growing demand. In addition, liquid hydrogen also has a wide range of civil and industrial applications, which is an important direction of new energy technology development. In particular, in the energy law of the people's Republic of China (Draft) issued by the National Energy Administration on 10 April 2020, hydrogen energy is listed as energy, which is the first time that China has legally confirmed that hydrogen energy belongs to energy [1]. The importance of liquid hydrogen as a clean energy shared by the military and civilians can be seen.

In the liquid hydrogen industry, there are dozens of liquid hydrogen plants worldwide, with a total liquid hydrogen capacity of 470 tons/day. North America accounts for more than $85 \%$ of the total global liquid hydrogen capacity. There are more than 15 liquid hydrogen plants in the United States, with a liquid hydrogen production capacity of more than 326 tons/day, ranking first in the world. Four liquid hydrogen plants in Europe have a liquid hydrogen capacity of 24 tons/day. There are 16 liquid hydrogen plants in Asia, with a total capacity of 38.3 tons/day, of which Japan accounts for two-thirds of the capacity in Asia. The only liquid hydrogen plants in use in China are Wenchang in Hainan, 101 Institute in Beijing, and Xichang Base, all serving for space rocket launches, with low production capacity and high cost, which directly restricts the application of liquid hydrogen in the high-end manufacturing, metallurgy, electronics, and energy industries [2]. Therefore, liquid hydrogen and the hydrogen energy industry have become the key direction of energy development in China.

As an important carrier of large-scale storage and transportation of liquid hydrogen, the cryogenic storage and transportation vessel of liquid hydrogen is the key equipment in the field of space and energy. The design and manufacture of liquid hydrogen storage and transportation vessels are supported by the scientific use of low temperature materials. It is an important guarantee for the safe, reliable, and long-term operation of the cryogenic propellant storage and transportation vessel to systematically and thoroughly grasp the comprehensive properties of the cryogenic materials of the storage and transportation containers. In the United States, Europe, Japan, and other countries, liquid hydrogen and other low temperature propellant storage and transportation containers have been widely used in space propulsion systems, civil energy, chemical, and other fields, who have accumulated a rich experience in material performance research and high efficiency and safe use of liquid hydrogen storage and transportation containers. They mastered the system of the low temperature material performance test method, and formed a perfect design, standard selection system, and specification.

In China, the design and development of cryogenic propellants, especially liquid hydrogen storage and transportation containers as well as the mechanical properties and selection standards of related materials have only been preliminarily studied in the aerospace field. However, the civil field is basically blank, the development of related technologies is relatively limited, and the relevant standard system is not perfect. In the past, the performance requirements of metal materials were only regulated to $77 \mathrm{~K}$ in the relevant standards of pressure vessels and metal materials in China, but there were no clear regulations on the performance parameters and design selection requirements of metal materials at the liquid hydrogen temperature. Generally, the material properties at $77 \mathrm{~K}$ are selected and determined, but there is a lack of data support. In recent years, the research on the properties of low-temperature metal materials has become an important direction of materials science. Scholars from all over the world have done significant work in this field. According to the published data, the Soviet Union studied this aspect earlier and involved many kinds of materials including nickel manganese steel, titanium alloy, aluminum alloy, and copper alloy, while the United States studied it later. However, later, with the continuous development of American space technology, they established a perfect material database for low-temperature materials, and the key data in the database were not released to the public. For example, the low-temperature material properties published 
by the National Institute of Standards and Technology (NIST) include the specific heat capacity, coefficient of linear expansion, Young's modulus, and thermal conductivity of aluminum alloy, stainless steel, titanium alloy, and other materials. It can be seen that the main properties are thee physical parameters, but there is no relevant report on the low-temperature mechanical properties of different brands of materials.

With the continuous improvement in the independent and controllable requirements of China's aerospace equipment, more and more attention has been paid to this aspect. However, the series and standards of low-temperature metal materials have not been established, and detailed data support is lacking. For example, the low-temperature design temperature of steel vessels in China's pressure vessel industry (GB150-2011) has been extended from 77 to $20 \mathrm{~K}$, and the minimum design temperature of aluminum vessels has reached $4.2 \mathrm{~K}$. Although the design temperature has been lowered to the liquid hydrogen temperature zone in the standard specification, the material strength and strength of pressure vessels in low-temperature environments have been improved. The lack of basic mechanical property data such as plasticity and impact toughness restricts the domestic independent production of cryogenic propellant storage and transportation container equipment to a great extent. In order to fully grasp the development status of liquid hydrogen storage and transportation container materials, the research status of cryogenic materials for liquid hydrogen storage and transportation containers was systematically reviewed in this paper including material category and low-temperature mechanical properties.

\section{Stainless Steel}

\subsection{Types of Stainless Steel Materials for Cryogenic Application}

Austenite stainless steel has good low temperature performance, which is the first choice of materials for low temperature working conditions and is also the most widely used material for liquid hydrogen storage and transportation vessels. As early as 1955, the United States first tried to use liquid hydrogen as aviation fuel and developed two stainless steel liquid hydrogen tanks on the wing tip [3]. Austenite in stainless steel belongs to face centered cubic structure crystal, which has superior plastic deformation ability. By adding a higher content of $\mathrm{Ni}$ and $\mathrm{Cr}$ in the alloy, the austenite has higher stability at low temperature. Therefore, with the decrease in temperature, the strength of austenitic stainless steel can be improved while maintaining superior plasticity and low temperature impact resistance. The composition elements of different grades of stainless steel are different, as shown in Table 1, which determines their macro properties and applications. Although the liquid hydrogen storage tank is mainly made of stainless steel, there is a lack of theoretical or standard guidance on what grade of stainless steel to choose for different applications and the comprehensive performance evaluation of stainless steel in the liquid hydrogen temperature zone. Austenitic stainless steel can be divided into $\mathrm{Cr}-\mathrm{Ni}-\mathrm{Mn}$ (200 series) and $\mathrm{Cr}-\mathrm{Ni}$ (300 series) according to its chemical composition. Because of its superior comprehensive performance [4,5], the 300 series is widely used in low temperature liquid storage and transportation containers, among which 304, 304L, 316, 316L, 321, 347, and so on are used. The difference in alloy elements of different grades of stainless steel also directly affects the final performance and application of materials. For example, 316L stainless steel has an added Mo element, which greatly improves the resistance of stainless steel to chloride ion corrosion. It is suitable for marine environments with high salt spray concentration. In comparison, 321 stainless steel has an added Ti element, which improves the resistance to intergranular corrosion and high temperature strength, therefore making it suitable for an environment with high requirements of corrosion resistance and heat resistance. In light of the specific application, the best material selection should be determined by considering the mechanical properties, corrosion resistance, welding performance, and cost of the materials. Additionally, 304 stainless steel was used in the $100 \mathrm{~m}^{3}$ liquid hydrogen tank for the domestic "50 project" hydrogen oxygen engine test run, while 321 stainless steel was used in the $300 \mathrm{~m}^{3}$ liquid hydrogen transport tank 
car at the Hainan large launch site. With the increasing demand for liquid hydrogen storage and transportation for low-temperature materials, it is necessary to carry out systematic comprehensive research on stainless steel materials for liquid hydrogen storage and transportation vessels, fully grasp the performance characteristics of different types and brands of stainless steel, and on this basis, formulate the material selection standards of stainless steel materials that meet the requirements of low temperature storage and transportation containers of liquid hydrogen.

Table 1. Chemical composition of austenite stainless steel commonly used in cryogenic temperature $[4,5]$.

\begin{tabular}{|c|c|c|c|c|c|c|c|c|}
\hline \multirow{2}{*}{ Alloy Grade } & \multicolumn{8}{|c|}{ Chemical Composition, $\%$} \\
\hline & $\mathrm{C}$ & Mn & Si & $\mathrm{Cr}$ & $\mathbf{N i}$ & $\mathbf{P}$ & $\mathrm{S}$ & Other \\
\hline 201 & 0.15 & $5.5-7.5$ & 1.00 & $16.0-18.0$ & $3.5-5.5$ & 0.06 & 0.03 & $0.25 \mathrm{~N}$ \\
\hline 202 & 0.15 & $7.5-10.0$ & 1.00 & $17.0-19.0$ & $4.0-6.0$ & 0.06 & 0.03 & $0.25 \mathrm{~N}$ \\
\hline 205 & $0.12-0.25$ & $14.0-15.5$ & 1.00 & $16.5-18.0$ & $1.0-1.75$ & 0.06 & 0.03 & $0.32-0.40 \mathrm{~N}$ \\
\hline 301 & 0.15 & 2.0 & 1.00 & $16.0-18.0$ & $6.0-8.0$ & 0.045 & 0.03 & \\
\hline 302 & 0.15 & 2.0 & 1.00 & $17.0-19.0$ & $8.0-10.0$ & 0.045 & 0.03 & \\
\hline 303 & 0.15 & 2.0 & 1.00 & $17.0-19.0$ & $8.0-10.0$ & 0.20 & 0.15 & $0.6 \mathrm{Mo}(\mathrm{b})$ \\
\hline 304 & 0.08 & 2.0 & 1.00 & $18.0-20.0$ & $8.0-10.5$ & 0.045 & 0.03 & \\
\hline $304 \mathrm{~L}$ & 0.03 & 2.0 & 1.00 & $18.0-20.0$ & $8.0-10.5$ & 0.045 & 0.03 & \\
\hline $304 N$ & 0.08 & 2.0 & 1.00 & $18.0-20.0$ & $8.0-10.5$ & 0.045 & 0.03 & $0.10-0.16 \mathrm{~N}$ \\
\hline 316 & 0.08 & 2.0 & 1.00 & $16.0-18.0$ & $10.0-14.0$ & 0.045 & 0.03 & 2.0-3.0Mo \\
\hline $316 \mathrm{~L}$ & 0.03 & 2.0 & 1.00 & $16.0-18.0$ & $10.0-14.0$ & 0.045 & 0.03 & 2.0-3.0Mo \\
\hline 310 & 0.25 & 2.0 & 1.50 & $24.0-26.0$ & $19.0-22.0$ & 0.045 & 0.03 & \\
\hline 321 & 0.08 & 2.0 & 1.00 & 17.0-19.0 & $9.0-12.0$ & 0.045 & 0.03 & $5 \times \% C \operatorname{minTi}$ \\
\hline
\end{tabular}

\subsection{Hydrogen Embrittlement of Austenitic Stainless Steel}

Hydrogen embrittlement refers to the phenomenon of material crack initiation and fracture caused by the diffusion of hydrogen molecules into the material. Due to the serious damage of hydrogen embrittlement to the structure, especially in a hydrogen environment, it needs special attention [6]. When the material is loaded in the smelting process or in the hydrogen environment, hydrogen molecules will gather at the internal stress concentration of the material, resulting in crack initiation, propagation, and fracture $[7,8]$. The theoretical mechanism of hydrogen embrittlement mainly includes hydride theory, hydrogen induced weak bond theory, and hydrogen induced local plastic deformation theory [9,10]. In austenitic stainless steel, because it is difficult for Fe and $\mathrm{H}$ atoms to form hydrides, the hydrogen embrittlement mechanism is mainly based on the theory of hydrogen induced local plastic deformation. For austenitic stainless steel, the stability of austenite at low temperature ensures its high hydrogen embrittlement resistance, which is one of the main reasons why austenitic stainless steel can be used in a liquid hydrogen environment. However, the stability of austenite phase has a great influence on hydrogen embrittlement resistance. For example, metastable 304 austenitic stainless steel has a lower hydrogen embrittlement resistance than 310 and 316 austenitic stainless steel with better phase stability [11]. In addition, long-term service in a liquid hydrogen environment or stress in a liquid hydrogen environment will also lead to the hydrogen embrittlement of austenitic stainless steel.

The microstructure of stainless steel is comprehensively affected by composition, processing technology, and heat treatment process. Different microstructures and surface states have different hydrogen embrittlement resistance. Lee [12] compared the hydrogen embrittlement characteristics of austenitic stainless steel by additive manufacturing with that of traditional austenitic stainless steel and found that the hydrogen embrittlement resistance of stainless steel by additive manufacturing did not decrease while the strength was improved. Lucas [13] studied the effect of surface roughness on the hydrogen embrittlement characteristics of stainless steel and revealed that the surface martensite transformation induced by cutting was the main cause of hydrogen embrittlement. Compared with 304, 310 stainless steel had higher stability and higher hydrogen embrittlement resistance. Fan [14] studied the effect of grain refinement on hydrogen embrittlement of 
304 stainless steel, and the results showed that grain refinement can reduce stress concentration and improve hydrogen embrittlement resistance. In addition, the study showed that austenitic stainless steel with a nano twin structure had high hydrogen embrittlement resistance $[15,16]$. Therefore, in order to improve the hydrogen embrittlement resistance of austenitic stainless steel as much as possible, it is particularly important to strictly control all aspects of material preparation and forming, maximize the stability of austenite, and reduce stress concentration. In addition, a lot of research work has been carried out from surface coating, cathodic protection, ion implantation, laser shot peening, and other aspects to improve the hydrogen embrittlement corrosion resistance of stainless steel [17-19]. With the increasing application of stainless steel in the field of liquid hydrogen storage and transportation, the understanding of hydrogen embrittlement also needs to be deepened. Therefore, it is of great practical significance to study the hydrogen embrittlement characteristics of different brands of austenitic stainless steel materials and different applications [20,21].

\subsection{Cryogenic Mechanical Properties of Stainless Steel}

Generally, with the decrease in temperature, the elastic modulus, tensile strength, and yield strength of the material increase, and the fatigue strength and endurance limit also increase [22,23]. The impact toughness is closely related to the crystal structure of the material. The face centered cubic crystal has better impact resistance at low temperature, while the body centered cubic crystal has worse impact resistance, The plasticity of materials at low temperature depends on the ductile brittle transition characteristics of materials. For materials without low-temperature brittle transition, the elongation increases with the decrease in temperature [23]. For materials with low-temperature brittle transition, the plasticity decreases sharply at low temperature, and cannot be applied to a low-temperature environment [21]. Cryogenic toughness is the most important evaluation index of cryogenic materials, and the test methods closely related to liquid hydrogen storage and transportation containers are as follows: low temperature impact toughness test (V-notch, German Society for testing and materials (DVM) sample), drop weight test, full thickness test (wide plate test, double tensile test, Esso test), fracture mechanics test (plane strain fracture toughness KIC and crack tip opening displacement cod method). The cryogenic Charpy (V-notch) impact toughness test is the most widely used, and the temperature corresponding to a certain absorption energy Akv or a certain percentage of fracture fiber (i.e., brittle transition temperature) in the impact test is used to evaluate the low temperature toughness of materials. Austenitic stainless steel belongs to a face centered cubic structure, which has high stability at low temperature. With the decrease in temperature, its plasticity and toughness will not decrease significantly.

In the early American Society of Mechanical Engineers (ASME) code, for vessels made of low carbon steel and some low alloy steels, when working below a certain temperature (the temperature is related to the thickness of the material), the Charpy (V-notch) impact test impact energy of the material is required to be no less than $20 \mathrm{~J}$. In the design of liquid hydrogen storage and transportation vessels, it is necessary to pay attention to the lowtemperature impact toughness of the material at a temperature of $20 \mathrm{~K}$. According to GB150, when the service temperature of austenitic stainless steel is higher than or equal to $-196{ }^{\circ} \mathrm{C}$, the low-temperature impact test can be avoided. However, ASME has more stringent requirements, which stipulates that the carbon content of austenitic stainless steel is lower than $0.1 \%$ when it is used above $-196{ }^{\circ} \mathrm{C}$. The base metal and heat affected zone can be exempted from the low temperature impact test, but when the carbon content is higher than $0.1 \%$, the service temperature without the low temperature impact test was higher than or equal to $-48{ }^{\circ} \mathrm{C}$. According to the Japanese Industrial Standards (JIS) specification for low temperature service of austenitic stainless steel, when the service temperature is lower than $-196{ }^{\circ} \mathrm{C}$, a low temperature impact test should be carried out [22]. The requirements of foreign standards for low temperature properties of stainless steel are higher than those of domestic standards, which shows that they pay more attention to low temperature impact 
toughness. Considering the influence of material type, batch, forming process, and heat treatment process on the microstructure and properties of materials, it is necessary to carry out low-temperature impact toughness testing of the base metal and weld for practical liquid hydrogen storage tank materials, and the performance of welded parts is usually slightly worse than that of the base metal, so the low-temperature $(20 \mathrm{~K})$ impact toughness evaluation of weld is particularly critical.

The tensile strength, yield strength, elastic modulus, and plasticity index of materials can be obtained by the tensile test. The electronic universal testing machine can be used to evaluate the low-temperature tensile properties of materials. As the basic data of materials, the tensile property index also plays an important role in the design of lowtemperature vessels. The tensile strength and yield strength of stainless steel increase with the decrease in temperature, while the plasticity of stainless steel reduces with the decrease in temperature, as shown in Figure 1. However, the reduction of plasticity is not that severe, which ensures that the ductility can be retained at cryogenic temperature, as shown in Figure 2. Materials with obvious brittle fracture at low temperature cannot be used in a cryogenic environment. The significant decrease in the plasticity at low temperature will induce brittle crack initiation and fracture risk. The plastic deformation ability of materials is closely related to the crystal structure of the materials. There is no brittle fracture for materials with aa face centered cubic structure (austenitic stainless steel, aluminum alloy, etc.). It can be seen from Figure 1 that the fracture toughness of 316 stainless steel increased with the decrease in temperature up to $77 \mathrm{~K}$. It showed a slight reduction at $20 \mathrm{~K}$ compared to that at $77 \mathrm{~K}$, but it was still higher than that at room temperature [23]. For the materials with a body centered cubic structure (martensitic steel, etc.), the plasticity decreased with the decrease in temperature, and there was obvious brittle fracture. Materials with a closely packed hexagonal structure (titanium alloy, etc.) were between the above two, but the plasticity at low temperature could also be improved by adjusting the material composition and microstructure [23]. It is very important for the design of storage and transportation containers to obtain the tensile properties of different materials at $20 \mathrm{~K}$ temperature. Therefore, it is necessary to carry out systematic and comprehensive testing of ultra-low temperature tensile properties $\left(\leq-196^{\circ} \mathrm{C}\right)$.

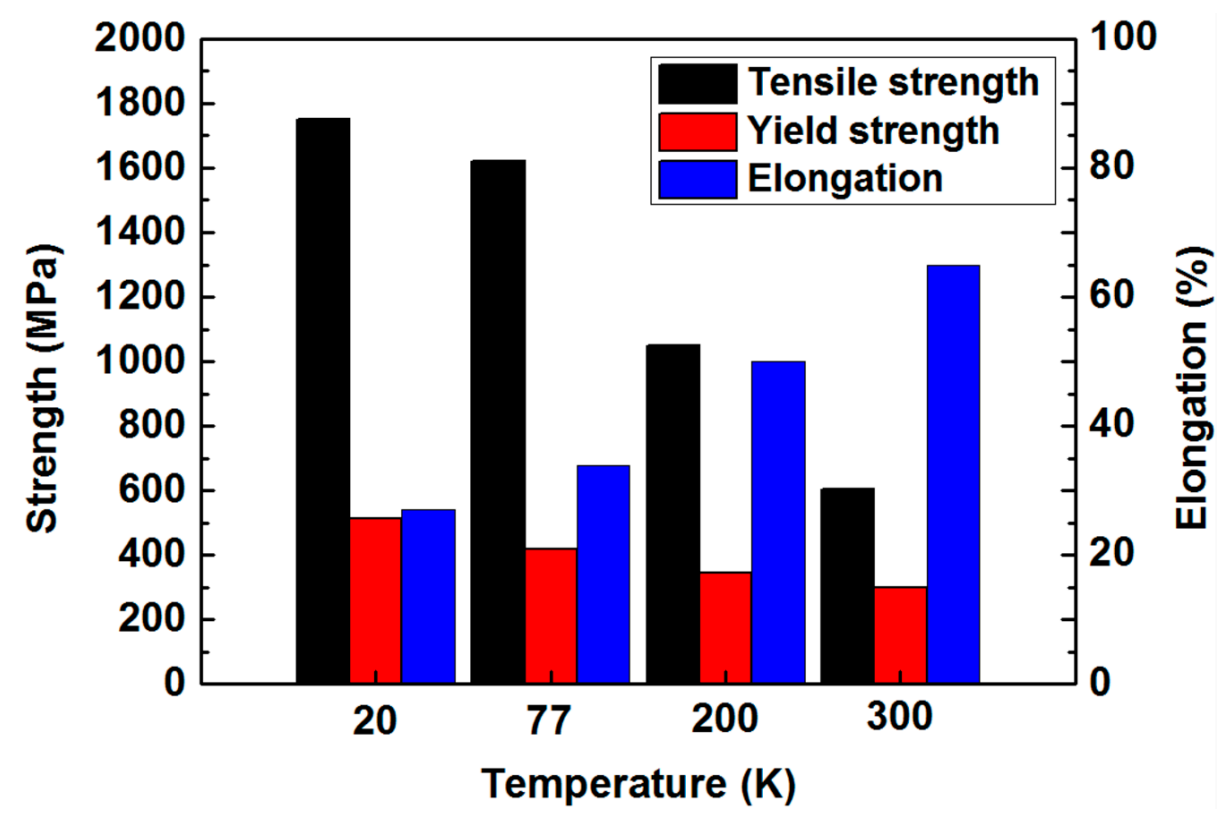

Figure 1. Cryogenic properties of $18 \mathrm{Cr}-8 \mathrm{Ni}$ stainless steel at different temperatures. 


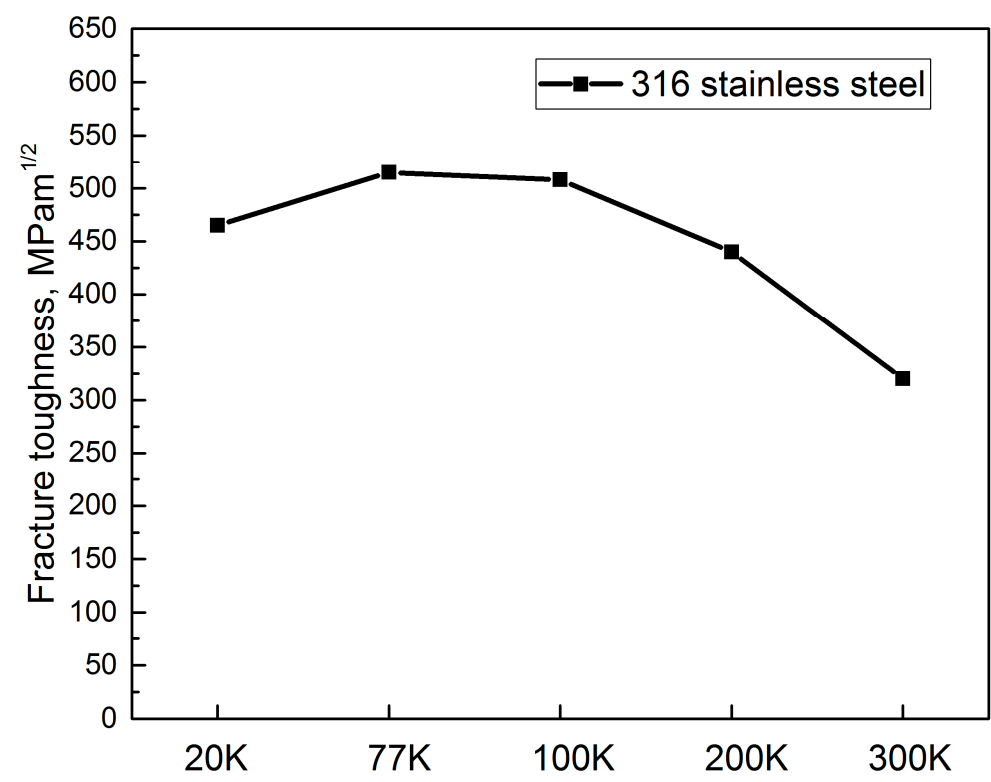

Figure 2. Cryogenic fracture toughness of 316 stainless steel at different temperatures.

\section{Aluminum Alloy}

\subsection{Types of Aluminum Alloy for Liquid Hydrogen Storage and Transportation}

Aluminum alloy has the same face centered cubic crystal structure as austenitic stainless steel, so it has no obvious ductile brittle transition temperature at low temperature, and also has high impact toughness. In addition, aluminum alloy also has the characteristics of high specific strength, good processability, and low sensitivity to hydrogen embrittlement, so it is widely used in liquid hydrogen containers. Particularly in aerospace propellant tanks, an aluminum alloy is an ideal low temperature material. The aluminum alloys used in low temperature mainly include solution hardening and precipitation hardening (aging hardening). The solution hardening alloys are usually Al-Mg alloys (5000 series) and $\mathrm{Al}-\mathrm{Mn}$ alloys (3000 series). The precipitation hardening alloys are mainly $\mathrm{Al}-\mathrm{Cu}-\mathrm{Mg}$ alloys (2000 series), Al-Mg-Si alloys (6000 series), and Al-Zn-Mg alloys (7000 Series). The chemical composition of aluminum alloys commonly used in low temperature is shown in Table 2 [24]. As early as 1970, the United States has carried out research on the application of hydrogen fuel in civil aircraft, where the liquid hydrogen storage tank was made of 2219 aluminum alloy, which was respectively arranged in the front and rear of the fuselage [25]. With the development of aeronautics and astronautics, aluminum alloy liquid hydrogen storage tanks have been applied in the field of rocket launching in the United States, in which 2195 aluminum alloys, 2029 aluminum alloys and 2219 aluminum alloys are used. In recent years, the space launch system jointly developed by NASA and Boeing has adopted a liquid hydrogen rocket, and its ultimate goal is to send human beings to Mars. The liquid hydrogen fuel tank is made of 2219 aluminum alloy and welded by friction stir welding [26]. The propellant tank of launch vehicles in China has developed from 5A06 alloys to 2A14 aluminum alloys and 2219 aluminum copper alloys. The 2A14 aluminum alloy has been used as the structural material of tanks thus far and is the main material of mature models in service. Furthermore, the 2219 alloy has also been determined as the structural material of the new generation of launch vehicle tanks in China [27], and the liquid hydrogen storage tank for cz-5 launch vehicle is also made of 2219 aluminum alloy [28]. With the increasing launch capacity of rockets, liquid hydrogen and liquid oxygen rockets are the future development trend, and the demand for aluminum alloy liquid hydrogen storage tanks will also increase in the future. 
Table 2. Chemical composition of aluminum alloys commonly used in cryogenic temperatures [24].

\begin{tabular}{ccccccccc}
\hline \multirow{2}{*}{ Alloy } & \multicolumn{7}{c}{ Chemical Composition, \% } \\
\cline { 2 - 8 } & $\mathbf{S i}$ & $\mathbf{F e}$ & $\mathbf{C u}$ & $\mathbf{M n}$ & $\mathbf{M g}$ & $\mathbf{Z n}$ & $\mathbf{C r}$ & $\mathbf{T i}$ \\
\hline 1100 & \multicolumn{2}{c}{$0.95(\mathrm{Si}+\mathrm{Fe})$} & $0.05-0.4$ & 0.05 & & & \\
2219 & 0.2 & 0.3 & $5.8-6.8$ & $0.2-0.4$ & 0.02 & 0.10 & $0.02-0.10$ \\
2014 & $0.5-1.2$ & 0.7 & $3.9-5.0$ & $0.4-1.2$ & $0.2-0.8$ & 0.25 & \\
3003 & 0.6 & 0.7 & $0.05-0.20$ & $1.0-1.5$ & & 0.10 & \\
3004 & 0.3 & 0.7 & 0.25 & $1.0-1.5$ & $0.8-1.3$ & 0.25 & $0.05-0.25$ \\
5083 & 0.4 & 0.4 & 0.1 & $0.4-1.0$ & $4.0-4.9$ & 0.25 & 0.15 \\
5086 & 0.4 & 0.5 & 0.1 & $0.2-0.7$ & $3.5-4.5$ & 0.25 & $0.05-0.25$ \\
5454 & 0.25 & 0.4 & 0.1 & $0.5-1.0$ & $2.4-3.0$ & 0.25 & $0.05-0.20$ & 0.15 \\
5456 & 0.25 & 0.4 & 0.1 & $0.5-1.0$ & $4.7-5.5$ & 0.25 & $0.05-0.20$ & 0.20 \\
6061 & $0.4-0.8$ & 0.7 & $0.15-0.4$ & 0.15 & $0.8-1.2$ & 0.25 & $0.04-0.35$ \\
7005 & 0.35 & 0.40 & 0.1 & $0.2-0.7$ & $1.0-1.8$ & $4.5-5.0$ & $0.06-0.20$ & $0.015-0.06$ \\
\hline
\end{tabular}

\subsection{Properties of Aluminum Alloy for Liquid Hydrogen Storage and Transportation}

The tensile strength and yield strength of aluminum alloy increase with the decrease in temperature, and its yield strength ratio of plasticity and notch is not sensitive. Therefore, aluminum alloys are also the main materials for liquid hydrogen tanks for space rocket launches. Liquid hydrogen tanks are usually produced by sheet metal forming, milling, welding, and other manufacturing technologies, among which welding technology has always been a hot spot in the research of liquid hydrogen tanks. Due to the change of microstructure in the weld and heat affected zone, there are three types of cracks $[29,30]$ in the welding area: crystallization cracks, liquefaction cracks, and storage cracks. According to the manufacturing quality standard of aerospace propellant tanks in China, the welded joint is not allowed to have cracks. The welding process is also accompanied by the generation of residual stress. As the existence of residual stress will reduce the fatigue strength and make it easy to fracture, it is necessary to eliminate the residual stress of the tank after welding [31,32]. In addition, the corrosion resistance and stress corrosion characteristics of the welding parts are also aspects of aluminum alloy tanks that need to be concerned. Many scholars have carried out research on the corrosion resistance of aluminum alloy weldments [33-36] and proposed some surface treatment methods to improve the corrosion resistance of aluminum alloy weldments [37]. Considering the application of a liquid hydrogen environment, the welding performance of the material is also a key index of material selection in the manufacturing process of low-temperature storage tanks. For example, the elongation segregation of 2A14 aluminum alloy welding joint and serious crack tendency exist [38]. The fusion welding method with concentrated energy density and without filler wire are not suitable for the material. However, at present, the commonly used welding methods in engineering are suitable for 2219 aluminum alloy $[39,40]$. In addition, the $7 x x x$ aluminum alloy with plastic decline or hydrogen induced brittleness in a liquid hydrogen environment is not suitable for making liquid hydrogen tanks [41-43].

\section{Titanium Alloy}

Titanium alloys have been widely used in the aerospace field due to their advantages of high specific strength, good corrosion resistance, high temperature resistance, low thermal conductivity, and small coefficient of expansion [44]. In addition, titanium alloys have excellent cryogenic performance. With the continuous development of aerospace and deep space exploration, the performance requirements of low temperature materials for aerospace structures are further improved. Titanium alloys are also very suitable for use in the aerospace field as a new low temperature material [44]. In 1981, the Apollo space rocket launched by NASA used titanium and titanium alloys as liquid helium and liquid hydrogen containers and structural pipes [45]. Pure titanium has a closely packed hexagonal structure at room temperature $\alpha$. When the temperature is above $855^{\circ} \mathrm{C}$, the 
isomeric transformation will take place and the body centered cubic structure will be formed as the $\beta$ phase, low temperature $\beta$. With the decrease in temperature, the plasticity and toughness of the phase decrease $\alpha$. Therefore, most of the titanium alloys used at low temperature are pure titanium $\alpha$ titanium alloy or a $\beta$ two phase titanium alloy with less phase content [46].

At present, low temperature titanium alloys have been initially used in the field of liquid rocket engines, mainly as structural materials such as in hydrogen storage tanks and hydrogen pump impellers of the hydrogen oxygen engine, greatly improving the thrust weight ratio, working life, and reliability of a liquid rocket engine [47]. However, the biggest problem in the application of titanium alloys at low temperature is that its elongation, impact toughness, and fracture toughness decrease with the decrease in temperature [48]. Therefore, scholars have carried out a lot of research in this area. By reducing the content of $\mathrm{C}, \mathrm{H}, \mathrm{O}$, and other interstitial elements and reducing the content of chlorine, the low temperature performance of titanium alloys can be effectively improved. Russia has been at the leading level in the world in the research and development of low-temperature titanium alloys and has developed a series of low aluminum low-temperature titanium alloys, among which OT4 and BT5-1 are widely used [49]. The United States has mainly focused on the development of low-temperature titanium alloys such as $\alpha$-Ti alloy TA7 ELI and $\alpha+\beta$ alloy TC4 ELI. As the main material of liquid hydrogen vessels and liquid hydrogen conduits, TC4 ElI was widely used in the Apollo project and achieved good results [49]. In the field of low-temperature titanium alloy research and development, China started relatively late, and has successively carried out the research and development of Ti-2Al$2.5 \mathrm{Zr}$, Ti-3Al-2.5Zr, CT20, and other low-temperature titanium alloys as well as obtained low-temperature titanium alloys with independent intellectual property rights [50-53].

\section{Cryogenic Composites}

With the continuous development of the aerospace field, the demand for lightweight fuel tanks is increasing. Composite materials have higher strength and lower density and have the potential to reduce weight by $25 \%$ compared with aluminum alloy tanks [26]. As a cryogenic liquid storage and transportation container, the cryogenic properties of composites have attracted extensive attention, and a large number of literatures have been reviewed in detail in recent years [54-59]. The low temperature mechanical properties of composites are affected by resin, fiber, and the interface. In general, with the decrease in temperature, the bonding strength of the polymer molecular chain increases, which makes the Young's modulus and tensile strength of resin matrix increase. However, with the decrease in temperature, the toughness of the resin matrix decreases. Unlike polymers, the strength of carbon fiber is less affected by temperature. With the decrease in temperature, the strength of a single carbon fiber will decrease, but the effect of this decrease on the overall composite can be ignored compared to the matrix resin or the interface between the fiber and resin. In addition, the mechanical properties of composite materials at low temperature are also related to the structural form, composite process, forming mode, and fiber direction of the composite materials. The fracture mechanism is more complex at low temperature. At present, most of the studies have focused on the low temperature mechanical properties of the resin matrix, but there has been little research on composite systems with fiber reinforced, and there is no reliable evaluation method and fracture criterion for the low-temperature fracture of fiber reinforced composites. This is also the direction where further research is needed for composite materials in the future [60].

In the process of temperature change, the thermal expansion of the composite is the main driving factor affecting its mechanical properties. The difference in the expansion coefficient of fiber and resin leads to different deformation modes and degrees during the cooling process [61]. The deformation modes of different types of microscopes and different directions of the same fiber are also different. This also determines the complexity of the micromechanical coordination mechanism in the process of composite temperature change. The deformation forms of resin, fiber, and composite materials in the cooling 
process are as follows: the resin shrinks with the decrease in temperature, resulting in compressive stress on the surface, while most carbon fibers expand horizontally and longitudinally with the decrease in temperature, resulting in tensile stress on the surface. With the decrease in temperature, glass fibers and basalt fibers both shrink horizontally and longitudinally, and the surface is subject to compressive stress, while aramid fibers will shrink horizontally and expand longitudinally [62]. Therefore, it is the foundation on which to study the modification of fiber reinforced composites and establish the fracture criterion of composites to deeply understand the expansion characteristics of resin and fiber to be able to establish the correlation mechanism between them and the micro crack initiation of composites.

As a liquid hydrogen storage and transportation container material, NASA has developed the cycom 5320-1/IM7 composite material as an alternative material for liquid hydrogen storage tanks. This material can completely avoid micro cracks caused by hydrogen penetration and can achieve a 30\% weight reduction and 20\% cost reduction compared with traditional aluminum alloy metal storage tanks [63]. Liquid hydrogen storage tank composite materials are usually laid by carbon fibers and cured by resin. The biggest problem is that hydrogen penetration leads to micro cracks, fracture, leakage, and other serious problems. NASA has developed a barrier membrane lining on the inner wall, which can effectively avoid the problem of hydrogen penetration [64,65]. In China, the research on composite structure began in the 1970s. In recent years, composite materials have been applied in the load-bearing structure of launch vehicles. However, the application of composite materials in liquid hydrogen storage tanks still requires systematic and in-depth research, and there are still many technical breakthroughs in resin materials, the molding process, low-temperature performance of materials, hydrogen permeation, and other aspects.

\section{Conclusions}

In order to meet the development of the liquid hydrogen industry in the future, the demand for liquid hydrogen storage and transportation containers is increasing. Therefore, it is of great significance to carry out systematic research on cryogenic materials and their cryogenic properties, in order to establish a cryogenic database of relevant materials. Stainless steel has excellent hydrogen brittleness resistance, good low temperature performance, weldability, and corrosion resistance, so it has been widely used in liquid hydrogen storage and transportation, especially in ground liquid hydrogen storage and transportation. However, the low-temperature mechanical properties of materials under specific environmental requirements need to be further improved. For example, the combination of corrosion resistance and low-temperature properties of storage tanks, the comprehensive evaluation of low-temperature mechanical properties, and stress corrosion properties of weldments in salt spray environment need to be considered. Aluminum alloys have been widely used in liquid hydrogen storage tanks for space launches both domestically and internationally. Compared with stainless steel, aluminum alloys have obvious advantages in lightweight, excellent formability, welding performance, and good corrosion resistance. At present, more research has focused on the optimization of an aluminum alloy welding method and low temperature mechanical properties after welding, corrosion resistance, and stress corrosion. Titanium alloys also have some advantages in high strength, lightweight and low temperature performance, but its advantages in forming and welding performance are not obvious, and the cost is relatively high, so its application is relatively less. In the field of space launch or space on orbit, lightweight storage and transportation containers are the future development trend, and composite materials are the most potential alternative material for liquid hydrogen storage and transportation containers. However, the basic theory, process, and low-temperature performance mechanism of composite materials are not mature enough, which also becomes the research direction that needs to be strengthened in the future. Generally speaking, the future research and development of liquid hydrogen storage and transportation container materials mainly include the following 
directions: (1) the establishment of a database of mechanical properties in conventional low-temperature materials (stainless steel, titanium alloy, aluminum alloy) in the liquid hydrogen temperature range; (2) development of new low temperature materials with high performance and low cost; and (3) research on the basic theory and technology of fiber reinforced composites.

Author Contributions: Conceptualization, Y.Q., H.Y., L.T. and L.W.; formal analysis, L.T.; investigation, L.W.; writing—original draft preparation, Y.Q.; writing—review and editing, H.Y., L.T. and L.W.; supervision, Y.Q.; project administration, Y.Q.; funding acquisition, Y.Q. All authors have read and agreed to the published version of the manuscript.

Funding: This research was funded by the National Natural Science Foundation of China, grant number 51906002.

Data Availability Statement: The study did not report any data.

Conflicts of Interest: The authors declare no conflict of interest.

\section{References}

1. Meng, X.; Gu, A.; Wu, X.; Zhou, J.; Liu, B.; Mao, Z. Prospect of high quality development of hydrogen energy industry in China. Sci. Technol. Rev. 2020, 38, 77-93.

2. Zhang, J.; Meng, J.; Lv, K.; Wang, X. Development status and trend of hydrogen application in China. New Mater. Ind. 2021, 1, 36-39.

3. Maniaci, D.C. Relative performance of a liquid hydrogen fueled commercial transport. In Proceedings of the 46th AIAA Aerospace Sciences Meeting and Exhibit, Reno, Nevada, 7-10 January 2008.

4. Park, W.S.; Yoo, S.W.; Kim, M.H.; Lee, J.M. Strain-rate effects on the mechanical behavior of the AISI 300 series of austenitic stainless steel under cryogenic environments. Mater. Des. 2010, 31, 3630-3640. [CrossRef]

5. DeSisto, T.S.; Carr, L.C. Low temperature mechanical properties of 300 series stainless steel and titanium. Adv. Cryog. Eng. 1961, $557,577-586$.

6. Mansilla, C. Hydrogen applications: Overview of the key economic issues and perspectives. Hydrog. Supply Chain 2018, $271,92$.

7. Lynch, S.P. Hydrogen embrittlement (HE) phenomena and mechanisms. Stress Corros. Crack. 2011, 30, 90-130.

8. Bernstein, I. The role of hydrogen in the embrittlement of iron and steel. Mater. Sci. Eng. 1970, 6, 1-19. [CrossRef]

9. McLellan, R.; Harkins, C. Hydrogen interactions with metals. Mater. Sci. Eng. 1975, 18, 5-35. [CrossRef]

10. Hwang, J.-S.; Kim, J.-H.; Kim, S.-K. Effect of PTFE coating on enhancing hydrogen embrittlement resistance of stainless steel 304 for liquefied hydrogen storage system application. Int. J. Hydrogen Energy 2020, 45, 9149-9161. [CrossRef]

11. Chen, B. Discussion on hydrogen induced brittle fracture of austenitic stainless steel. Metall. Mater. 2020, 40, 165-167.

12. Lee, D.; Sun, B.; Lee, S.; Ponge, D.; Jägle, E.; Raabe, D. Comparative study of hydrogen embrittlement resistance between additively and conventionally manufactured 304L austenitic stainless steels. Mater. Sci. Eng. A 2021, 803, 140499. [CrossRef]

13. Queiroga, L.R.; Marcolino, G.F.; Santos, M.; Rodrigues, G.; dos Santos, C.E.; Brito, P. Influence of machining parameters on surface roughness and susceptibility to hydrogen embrittlement of austenitic stainless steels. Int. J. Hydrogen Energy 2019, 44, 29027-29033. [CrossRef]

14. Fan, Y.; Zhang, B.; Wang, J.; Han, E.-H.; Ke, W. Effect of grain refinement on the hydrogen embrittlement of 304 austenitic stainless steel. J. Mater. Sci. Technol. 2019, 35, 2213-2219. [CrossRef]

15. Fan, Y.; Cui, F.; Lu, L.; Zhang, B. A nanotwinned austenite stainless steel with high hydrogen embrittlement resistance. J. Alloys Compd. 2019, 788, 1066-1075. [CrossRef]

16. Ueki, S.; Oura, R.; Mine, Y.; Takashima, K. Micro-mechanical characterisation of hydrogen embrittlement in nano-twinned metastable austenitic stainless steel. Int. J. Hydrogen Energy 2020, 45, 27950-27957. [CrossRef]

17. Huang, S.; Ma, D.; Sheng, J.; Agyenim-Boateng, E.; Zhao, J.; Zhou, J. Effects of laser peening on tensile properties and martensitic transformation of AISI 316L stainless steel in a hydrogen-rich environment. Mater. Sci. Eng. A 2020, 788, 139543. [CrossRef]

18. Chen, X.; Zhang, H.; Zhao, C.; Xu, L. Effect of Cathodic Protection Potentials on Susceptibility to Hydrogen Embrittlement of E550 Steel. Corros. Sci. Prot. Technol. 2016, 28, 144-148.

19. Zhou, P.; Li, W.; Li, Y.; Jin, X. The Effect of MoS2 Content on the Protective Performance of Ni-MoS2 Composite Coatings against Hydrogen Embrittlement in High Strength Steel. J. Electrochem. Soc. 2016, 164, D23. [CrossRef]

20. Xiuqing, X.; Junwei, A.; Chen, W.; Jing, N. Study on the hydrogen embrittlement susceptibility of AISI 321 stainless steel. Eng. Fail. Anal. 2021, 122, 105212. [CrossRef]

21. Guo, Z.; Ju, Y. Status and problems of cryogenic liquid hydrogen storage. Cryog. Supercond. 2019, 47, $24-32$.

22. Qiu, Z.; Zhang, G.; Wu, Z. Low temperature steel and its application. Petrochem. Equip. Technol. 2004, 25, 43-46.

23. Duthil, P. Material Properties at Low Temperature. arXiv 2015, arXiv:1501.07100.

24. Chen, G. Cryogenic Engineering Materials; Zhejiang University Press: Hangzhou, China, 1998.

25. Brewer, G.D. Hydrogen Aircraft Technology; CRC Press: Boca Raton, FL, USA, 1991. 
26. Verstraete, D.; Hendrick, P.; Pilidis, P.; Ramsden, K. Hydrogen fuel tanks for subsonic transport aircraft. Int. J. Hydrogen Energy 2010, 35, 11085-11098. [CrossRef]

27. Liu, L.; Li, Z.; Li, Q.; Li, T. Selection of tank materials. New Technol. New Prod. China 2020, 4, 80-81.

28. Wang, Z. Long March 5 rocket fuel tank made of aluminum alloy. Nonferrous Met. Process. 2017, 46, 6-9.

29. Gong, B. The common welding crack and prevent methods in aluminium and aluminium alloy. Light Met. 2012, 9, 66-70.

30. Jha, A.K.; Murty, S.N.; Diwakar, V.; Kumar, K.S. Metallurgical analysis of cracking in weldment of propellant tank. Eng. Fail. Anal. 2003, 10, 265-273. [CrossRef]

31. Viswanath, V.; Asraff, A.K.; Jayesh, P.; Thomas, S.M.; Krishnakumar, R. Structural Integrity Assessment of a Propellant tank in Presence of Welding Residual Stresses. Proc. Struct. Integr. 2019, 14, 442-448. [CrossRef]

32. Peet, M.; Stuwer, A.; Preuss, M.; Withers, P.J. Microstructure mechanical properties and residual stress as a function of welding speed in aluminum AA5083 friction stir welding. Acta Mater. 2003, 5, 4791-4801.

33. Prabhuraj, P.; Rajakumar, S. Experimental Investigation on Corrosion Behavior of Friction Stir Welded AA7075-T651 Aluminium Alloy under 3.5\% wt $\mathrm{NaCl}$ Environment; Elsevier BV: Amsterdam, The Netherlands, 2021; Volume 45, pp. 5878-5885.

34. Jariyaboon, M.; Davenport, A.; Ambat, R.; Connolly, B.; Williams, S.; Price, D. The effect of welding parameters on the corrosion behaviour of friction stir welded AA2024-T351. Corros. Sci. 2007, 49, 877-909. [CrossRef]

35. Wadeson, D.; Zhou, X.; Thompson, G.; Skeldon, P.; Oosterkamp, L.D.; Scamans, G. Corrosion behaviour of friction stir welded AA7108 T79 aluminium alloy. Corros. Sci. 2006, 48, 887-897. [CrossRef]

36. Entringer, J.; Meisnar, M.; Reimann, M.; Blawert, C.; Zheludkevich, M.; Dos Santos, J.F. The effect of grain boundary precipitates on stress corrosion cracking in a bobbin tool friction stir welded Al-Cu-Li alloy. Mater. Lett. X 2019, 2, 100014. [CrossRef]

37. Wu, S.-D.; Cheng, W.-Y.; Yang, J.H.; Yang, C.H.; Liao, S.Y. The corrosion protection study on inner surface from welding of aluminum alloy 7075-T6 hydrogen storage bottle. Int. J. Hydrogen Energy 2016, 41, 570-596. [CrossRef]

38. Jha, A.K.; Narayanan, P.R.; Sreekumar, K.; Sinha, P.P. Cracking of Al-4.5Zn-1.5Mg aluminium alloy propellant tank-A metallurgical investigation. Eng. Fail. Anal. 2010, 17, 562-570. [CrossRef]

39. Yan, D.; Guo, Y.; Dong, M.; Wu, H.; Zhang, L. Research and Analysis on characteristics of 2A14 and 2219 aluminum alloys for tank structure. Missile Space Deliv. Technol. 2019, 102-107.

40. Li, X.; Song, Y.; Lu, Z.; Sun, Y. High frequency energy coupling pulsed TIG welding process on 2219 aluminum alloy. Trans. China Weld. Inst. 2015, 36, 17-20.

41. Moshtaghi, M.; Safyari, M.; Hojo, T. Effect of solution treatment temperature on grain boundary composition and environmental hydrogen embrittlement of an Al-Zn-Mg-Cu alloy. Vacuum 2021, 184, 109937. [CrossRef]

42. Kuramoto, S.; Okahana, J.; Kanno, M. Hydrogen assisted intergranular crack propagation during environmental embrittlement in an Al-Zn-Mg-Cu Alloy. Mater. Transcation 2001, 42, 2140-2143. [CrossRef]

43. Safyari, M.; Moshtaghi, M.; Kuramoto, S. Effect of strain rate on environmental hydrogen embrittlement susceptibility of a severely cold-rolled Al-Cu alloy. Vacuum 2020, 172, 109057. [CrossRef]

44. Liu, W.; Du, Y. Research status of low temperature titanium alloy. Rare Met. Lett. 2007, 26, 6-10.

45. Boyer, H. Atlas Of Stress-Strain Curves; ASM International: Materials Park, OH, USA, 2002.

46. Nagai, K.; Ishikawa, K. Deformation and Fracture Characteristics of Titanium Alloys at Low Temperatures. Tetsu Hagane 1989, 75, 707-715. [CrossRef]

47. Xu, A.; Wan, H.; Liang, C. Application status and development trend of low temperature titanium alloy. J. Netshape Form. Eng. 2020, 12, 145-156.

48. Qu, Y.; Yuan, X.; Xie, H.; Niu, Y.; Tao, Q.; Tang, Z. Research and application status and development trend of low temperature titanium alloy. Mech. Eng. Autom. 2009, 1, 189-191.

49. Yu, Y.; Jiang, P.; Li, S. Development and application of low temperature titanium alloy at home and abroad. Dev. Appl. Mater. 2014, 29, 118-122.

50. Sun, Q.Y.; Gu, H.C. Tensile and Low-cycle Fatigue Behavior of Commercially Pure Titanium and Ti-5Al2.5Sn Alloy at 293 and 77 K. Mater. Sci. Eng. A 2001, 316, 80-86. [CrossRef]

51. Ghisi, A.; Mariani, S. Mechanical Characterization of Ti-5Al-2.5Sn ELI Alloy at Cryogenic and Room Temperatures. Int. J. Fract. 2007, 146, 61-77. [CrossRef]

52. Singh, G.; Bajargan, G.; Datta, R.; Ramamurty, U. Deformation and Strength of Ti-6Al-4V Alloyed with B at Cryogenic Temperatures. Mater. Sci. Eng. A 2014, 611, 45-57. [CrossRef]

53. Du, Y.; Cai, X.; Yang, G. Analysis of the Relationship between Strain Behavior and Microstructure of CT20 Titanium Alloy at 20 K. Titan Ind. Prog. 2005, 6, 20-23.

54. Schutz, J.B. Properties of composite materials for cryogenic applications. Cryogenics 1998, 38, 3-12. [CrossRef]

55. Ma, Z.; Xi, R. Low temperature properties of composite materials. Vac. Cryog. 1985, 2, 22-29.

56. Liu, K.; Wang, R.; Shi, Y.; Gu, A. Low temperature properties of fiber reinforced polymer matrix composites. Cryog. Eng. 2006, 5 , 35-44.

57. Horiuchi, T.; Ooi, T. Cryogenic properties of composite materials. Cryogenics 1995, 35, 9. [CrossRef]

58. Sethi, S.; Ray, B.C. Mechanical Behavior of Polymer Composites at Cryogenic Temperatures; Springer Science and Business Media LLC: Berlin, Germany, 2013; pp. 59-113.

59. Yano, O.; Yamaoka, H. Cryogenic properties of polymers. Prog. Polym. Sci. 1995, 20, 585-613. [CrossRef] 
60. Hohe, J.; Neubrand, A.; Fliegener, S.; Beckmann, C.; Schober, M.; Weiss, K.P.; Appel, S. Performance of fiber reinforced materials under cryogenic conditions-A review. Compos. Part A Appl. Sci. Manuf. 2020, 141, 106226. [CrossRef]

61. Slifka, A.J.; Smith, D.R. Thermal expansion of an E-glass/vinyl ester composite from 4 to 293 K. Int. J. Thermophys. 1997, 18, 1249-1256. [CrossRef]

62. Sápi, Z.; Butler, R. Properties of cryogenic and low temperature composite materials-A review. Cryogenics 2020, 111, 103190. [CrossRef]

63. Gomeza, A.; Smith, H. Liquid hydrogen fuel tanks for commercial aviation: Structural sizing and stress analysis. Aerosp. Sci. Technol. 2019, 95, 105438. [CrossRef]

64. Sharke, P. H2 Tank Testing. Mech. Eng. Mag. 2004, 126, 20.

65. Heydenreich, R. Cryotanks in future vehicles. Cryogenics 1998, 38, 125-130. [CrossRef] 